\title{
Perianesthetic death: a 10-year retrospective observational study in a Japanese university hospital
}

\author{
Mariko Sato, Mitsuru Ida ${ }^{*}$, Yusuke Naito and Masahiko Kawaguchi
}

\begin{abstract}
Background: Studies reporting on perianesthetic death and anesthesia-related death are limited. The present study aimed to assess the incidence of perianesthetic death and its relation to anesthesia and to describe the patient characteristics and main events leading to death in cases of anesthesia-related death and anesthesia-contributory death.

Methods: We conducted a retrospective chart review of patients in whom anesthesia procedures were performed by anesthesiologists at a Japanese tertiary hospital between January 2008 and December 2017. Perianesthetic death was defined as death occurring within $48 \mathrm{~h}$ of an anesthetic, and it was divided into the following three categories: anesthesia-related death, anesthesia-contributory death, and nonanesthesia-related death. Patient demographics and perioperative factors were analyzed in cases of anesthesia-related death and anesthesia-contributory death.

Results: Among 46,378 patients who underwent anesthetics, 41 experienced perianesthetic death, with an incidence of 8.8/10,000 anesthetics (95\% confidence interval [Cl], 6.1-11.6). No patient experienced anesthesiarelated death, whereas 10 experienced anesthesia-contributory death, with an incidence of $2.1 / 10,000$ (95\% Cl, 0.693.6), and 31 experienced nonanesthesia-related death, with an incidence of 6.8/10,000 (95\% Cl, 4.2-9.1). The events leading to anesthesia-contributory death were hypovolemia, myocardial infarction, arrhythmia, and respiratory failure, and they occurred during anesthesia maintenance in 5 patients and after surgery in 5 patients.

Conclusions: The incidence of perianesthetic death was 8.8/10,000 anesthetics; however, anesthesia-related death was not detected. Ten patients experienced anesthesia-contributory death, and hypovolemia during or after surgery was most frequently associated with anesthesia-contributory death.
\end{abstract}

Keywords: Anesthesia, Mortality, Perioperative period

\section{Introduction}

Postoperative death, which is defined as death within 30 days of surgery, accounts for $7.7 \%$ of all deaths globally, and surgery is the third most common contributor to death [1]. In particular, death within $48 \mathrm{~h}$ of an anesthetic is defined as perianesthetic death, and it is a serious issue among anesthesiologists [2, 3].

Studies focusing on perioperative cardiac arrest have been published; however, studies focusing on perianesthetic death and anesthesia-related death are limited [39]. Two analyses of anesthesia-related death based on

\footnotetext{
* Correspondence: nwnh0131@yahoo.co.jp

Department of Anesthesiology, Nara Medical University, 840 Shijo-cho, Kashihara, Nara 634-8522, Japan
}

closed claims analysis and death certificates have been reported, but both analyses failed to provide denominators, making interpretation of the percentage of perianesthetic death difficult $[8,9]$. One retrospective analysis of the quality assurance database of a community-based anesthesiology group practice revealed that the perianesthetic death rate and anesthesia-related death rate were $7.53 / 10,000$ cases and $0.05 / 10,000$ cases, respectively [3]. However, these rates vary depending on the institution and the study population, and limited information is available on the incidence of perianesthetic death and its relation to anesthesia in Japan.

Therefore, in the present study, we aimed to assess the incidence of perianesthetic death and its relation to 
anesthesia at a Japanese tertiary hospital and to describe the patient characteristics and main events leading to death in cases of anesthesia-related death and anesthesia-contributory death.

\section{Methods}

\section{Ethical approval}

This retrospective observational study was approved by the Institutional Review Board of Nara Medical University (Kashihara, Nara, Japan; Chairperson Prof. M. Yoshizumi; approval no. 2964; December 17, 2018). The requirement of informed consent was waived because of the retrospective nature of this study.

\section{Patient selection}

We included patients who underwent anesthetics performed under general and local anesthesia managed by anesthesiologists at Nara Medical University between January 2008 and December 2017. We excluded patients who underwent anesthesia procedures performed in the emergency room or general ward without anesthesiologists.

Nara Medical University Hospital is a 992-bed tertiary care referral center with 15 operation rooms, including 1 hybrid operation room. Anesthesia information was obtained from our database, which had data provided by each anesthesiologist. We reviewed both electronic medical records and diagnosis procedure combination systems and extracted all patients who died by the first discharge after surgery. Among these patients, we identified those who died within $48 \mathrm{~h}$ of anesthetics.

\section{Definition of perianesthetic death}

Perianesthetic death was defined as death within $48 \mathrm{~h}$ of an anesthetic [2]. Perianesthetic death was divided into the following three categories: anesthesia-related death (death solely attributable to either the anesthesia provider or the anesthetic technique), anesthesiacontributory death (death in which the anesthesia role could not be entirely excluded), and nonanesthesiarelated death [3]. In cases of anesthesia-related death and anesthesia-contributory death, we identified the pathophysiological processes that best described the sequence of events [8]. The classifications of death and pathophysiological processes were performed independently by two researchers (MI and $\mathrm{YN}$ ), and any disagreement was resolved by discussion with another researcher (MK).

\section{Explanatory variables}

Data on patient characteristics, including sex, age, American Society of Anesthesiologists-Physical Status (ASA-PS), surgery circumstance (elective or emergency), surgery type, and anesthesia type, were collected. The surgery type was categorized according to the classification provided by the Japanese Society of Anesthesiologists. Burn surgery appears to be a high-risk procedure, but it is difficult to classify with the existing classification. Therefore, we added "burn surgery" to the existing classification. The anesthesia type was categorized as follows: general anesthesia with inhalation anesthesia, general anesthesia with total intravenous anesthesia, spinal anesthesia, epidural anesthesia, combined spinal and epidural anesthesia, and peripheral nerve block.

\section{Statistical analysis}

The details of patients who experienced anesthesiarelated death and anesthesia-contributory death are summarized. The incidence rate is expressed as occurrence in 10,000 anesthetics. The Wilson method was used to calculate $95 \%$ confidence interval (CI). In patients who experienced perianesthetic death, explanatory variables were analyzed using the Mann-

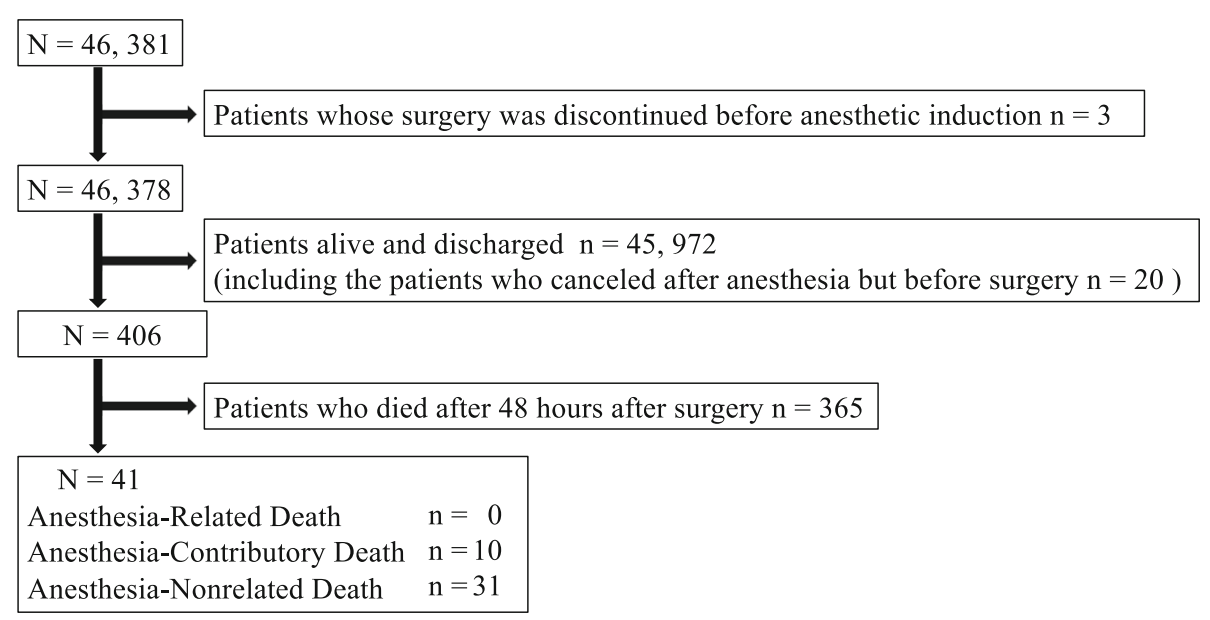

Fig. 1 Patient flowchart 
Table 1 Patients' background of the patients' experienced perianesthetic death or not

\begin{tabular}{|c|c|c|}
\hline & Perianesthetic death $(-)(n=46,337)$ & Perianesthetic death $(+)(n=41)$ \\
\hline Age (years) & $59.00[36.00,71.00]$ & $73.00[59.00,81.00]$ \\
\hline$<1$ & $863(1.9)$ & $2(4.9)$ \\
\hline $1 \leqq<3$ & $923(2.0)$ & $0(0.0)$ \\
\hline $3 \leqq<6$ & $905(2.0)$ & $0(0.0)$ \\
\hline $6 \leqq,<20$ & $2822(6.1)$ & $2(4.9)$ \\
\hline $20 \leqq,<65$ & $22,403(48.3)$ & $9(22.0)$ \\
\hline $65 \leqq,<75$ & $10,777(23.3)$ & $11(26.8)$ \\
\hline $75 \leqq$ & $7644(16.5)$ & $17(41.5)$ \\
\hline Male & $21,597(46.6)$ & $29(70.7)$ \\
\hline \multicolumn{3}{|l|}{ ASA-PS } \\
\hline 1 & $14,514(31.3)$ & $0(0.0)$ \\
\hline$\|$ & $26,880(58.0)$ & $0(0.0)$ \\
\hline III & $4628(10.0)$ & $5(12.2)$ \\
\hline IV & $298(0.6)$ & $12(29.3)$ \\
\hline v & $17(0.0)$ & $24(58.5)$ \\
\hline Emergency surgery & $7475(16.1)$ & $37(90.2)$ \\
\hline \multicolumn{3}{|l|}{ Type of surgery } \\
\hline Neuro & $4162(9.0)$ & $10(24.4)$ \\
\hline Thoracic & $2247(4.8)$ & $2(4.9)$ \\
\hline Cardiac & $1986(4.3)$ & $12(29.3)$ \\
\hline Esophageal & $211(0.5)$ & $1(2.4)$ \\
\hline Upper abdominal & $4216(9.1)$ & $1(2.4)$ \\
\hline Lower abdominal & $9912(21.4)$ & $11(26.8)$ \\
\hline Cesarean section & $3187(6.9)$ & $1(2.4)$ \\
\hline Head, neck, pharyngeal, and laryngeal & $7137(15.4)$ & $0(0.0)$ \\
\hline Chest wall abdominal wall and perineum & $2344(5.1)$ & $0(0.0)$ \\
\hline Spine & $2113(4.6)$ & $0(0.0)$ \\
\hline Hip joint and limbs & $6120(13.2)$ & $1(2.4)$ \\
\hline Examination & $671(1.4)$ & $0(0.0)$ \\
\hline Electroconvulsive therapy & $973(2.1)$ & $0(0.0)$ \\
\hline Others & $724(1.6)$ & $0(0.0)$ \\
\hline Burn & $316(0.7)$ & $0(0.0)$ \\
\hline Cancel after anesthesia induction & $18(0.0)$ & $2(4.9)$ \\
\hline \multicolumn{3}{|l|}{ Type of anesthesia } \\
\hline General anesthesia with inhalation anesthetics & $31,894(68.8)$ & $41(100)$ \\
\hline General anesthesia with TIVA & $9720(21.0)$ & $0(0.0)$ \\
\hline Spinal anesthesia & $4122(8.9)$ & $0(0.0)$ \\
\hline Epidural anesthesia & $420(0.9)$ & $0(0.0)$ \\
\hline Combined of spinal and epidural anesthesia & $142(0.3)$ & $0(0.0)$ \\
\hline Peripheral nerve block & $39(0.1)$ & $0(0.0)$ \\
\hline
\end{tabular}

ASA-PS American Society of Anesthesiologists-Physical Status, TIVA total intravenous anesthesia

Whitney $U$ test or Fisher's exact test. Patient age was categorized as follows: < 1 year, 1 to $<3$ years, 3 to < 6 years, 6 to $<20$ years, 20 to $<65$ years, 65 to $<75$ years, and $\geq 75$ years. All analyses were performed using SPSS version 22.0 (IBM Corp., Armonk, NY, USA). The level of statistical significance was set at a $p$ value $<0.05$.

\section{Results}

During the 10-year study period, 46,378 anesthetics were performed in our hospital. Of 406 patients who died by the first discharge after surgery, 41 experienced perianesthetic death, with an incidence of 8.8/10,000 anesthetics (95\% CI, 6.1-11.6) (Fig. 1, Table 1). As shown in Table 1, the rate of perianesthetic death was high in the elderly, patients 
Table 2 Backgrounds of patients who experienced nonanesthesia-related death and those who experienced anesthesia-contributory death

\begin{tabular}{|c|c|c|c|}
\hline & Nonanesthesia-related death $(n=31)$ & Anesthesia-contributory death $(n=10)$ & $p$ value \\
\hline Age (years) & $73.00[53.5,81.00]$ & $74.50[61.75,81.75]$ & 0.54 \\
\hline$<1$ & $2(6.5)$ & $0(0.0)$ & 0.84 \\
\hline $1 \leqq<3$ & $0(0.0)$ & $0(0.0)$ & \\
\hline $3 \leqq<6$ & $0(0.0)$ & $0(0.0)$ & \\
\hline $6 \leqq,<20$ & $1(3.2)$ & $1(10.0)$ & \\
\hline $20 \leqq,<65$ & $7(22.6)$ & $2(20.0)$ & \\
\hline $65 \leqq,<75$ & $9(29.0)$ & $2(20.0)$ & \\
\hline $75 \leqq$ & $12(38.7)$ & $5(50.0)$ & \\
\hline Male & $22(71.0)$ & $7(70.0)$ & 1 \\
\hline ASA-PS & & & 0.4 \\
\hline । & $0(0.0)$ & $0(0.0)$ & \\
\hline$\|$ & $0(0.0)$ & $0(0.0)$ & \\
\hline III & $2(6.5)$ & $3(30.0)$ & \\
\hline IV & $10(32.3)$ & $2(20.0)$ & \\
\hline $\mathrm{v}$ & $19(61.3)$ & $5(50.0)$ & \\
\hline Emergency surgery & $30(96.8)$ & $7(70.0)$ & 0.04 \\
\hline Type of surgery & & & 0.57 \\
\hline Neuro & $10(32.3)$ & $0(0.0)$ & \\
\hline Thoracic & $2(6.5)$ & $0(0.0)$ & \\
\hline Cardiac & $7(22.6)$ & $5(50.0)$ & \\
\hline Esophageal & $0(0.0)$ & $1(10.0)$ & \\
\hline Upper abdominal & $0(0.0)$ & $1(10.0)$ & \\
\hline Lower abdominal & $8(25.8)$ & $3(30.0)$ & \\
\hline Cesarean section & $1(3.2)$ & $0(0.0)$ & \\
\hline Head, neck, pharyngeal, and laryngeal & $0(0.0)$ & $0(0.0)$ & \\
\hline Chest wall abdominal wall and perineum & $0(0.0)$ & $0(0.0)$ & \\
\hline Spine & $0(0.0)$ & $0(0.0)$ & \\
\hline Hip joint and limbs & $1(3.4)$ & $0(0.0)$ & \\
\hline Examination & $0(0.0)$ & $0(0.0)$ & \\
\hline Electroconvulsive therapy & $0(0.0)$ & $0(0.0)$ & \\
\hline Others & $0(0.0)$ & $0(0.0)$ & \\
\hline Burn & $0(0.0)$ & $0(0.0)$ & \\
\hline Cancel after anesthesia induction & $2(6.5)$ & $0(0.0)$ & \\
\hline Type of anesthesia & & & 1 \\
\hline General anesthesia with inhalation anesthetics & $31(100)$ & $10(100)$ & \\
\hline General anesthesia with TIVA & $0(0.0)$ & $0(0.0)$ & \\
\hline Spinal anesthesia & $0(0.0)$ & $0(0.0)$ & \\
\hline Epidural anesthesia & $0(0.0)$ & $0(0.0)$ & \\
\hline Combination of spinal and epidural anesthesia & $0(0.0)$ & $0(0.0)$ & \\
\hline Peripheral nerve block & $0(0.0)$ & $0(0.0)$ & \\
\hline General anesthesia & $31(100)$ & $10(100)$ & 1 \\
\hline Pathophysiological process of death & & & 0.26 \\
\hline Respiratory & $1(3.2)$ & $1(10.0)$ & \\
\hline Arrhythmia & $2(6.5)$ & $1(10.0)$ & \\
\hline Myocardial infarction & $4(12.9)$ & $2(20.0)$ & \\
\hline Hypovolemia & $13(41.9)$ & $6(60.0)$ & \\
\hline Central neurologic disorders & $11(35.5)$ & $0(0.0)$ & \\
\hline
\end{tabular}


undergoing emergency surgery, and patients with a high ASA-PS. There was no anesthesia-related death. On the other hand, there were 10 anesthesia-contributory deaths, with an incidence of 2.1/10,000 anesthetics (95\% CI, 0.693.6), and 31 nonanesthesia-related deaths, with an incidence of 6.8/10,000 anesthetics (95\% CI, 4.2-9.1) (Table 2). Among the 41 patients, nonanesthesia-related death was more common in those undergoing emergency surgery $(p=0.04)$. Table 3 presents the details, including the pathophysiological mechanisms associated with the 10 anesthesia-contributory deaths. Overall, the events associated with anesthesia-contributory death were hypovolemia, myocardial infarction, arrhythmia, and respiratory failure. These events occurred during anesthesia maintenance in five 5 and after surgery in 5 patients.

\section{Discussion}

In the present study, the overall incidence of perianesthetic death was 8.8/10,000 anesthetics (95\% CI, 6.1-11.6), whereas anesthesia-related death was not detected. Additionally, the incidence of anesthesiacontributory death was 2.1/10,000 anesthetics (95\% CI, 0.69-3.6), and it was associated with hypovolemia, cardiac infarction, arrhythmia, and respiratory failure and was more common in elective surgery.

Previous studies have reported perianesthetic mortality using different definitions. Kawashima et al. used the definition of mortality occurring in the operating room and within seven postoperative days with accompanying critical events during surgery, whereas
Lagasse et al. and Pollard et al. used the definition of death occurring within $48 \mathrm{~h}$ of anesthesia induction $[2,3,7]$. Our study used the latter definition, and the incidence of perianesthetic death $(8.8 / 10,000)$ was similar to that reported in a recent study $(7.5 / 10,000)$ [3]. Furthermore, as expected, age, emergency surgery, and high ASA-PS were associated with perianesthetic death, and these findings are consistent with the findings of previous studies $[3,8,10,11]$.

Fortunately, there was no anesthesia-related death during the 10-year study period. This might be because our sample size was limited and there were no perianesthetic deaths associated with failed ventilation, aspiration of gastric contents, and accidental bolus of narcotics, which can lead to anesthesia-related death and anesthesiarelated cardiac arrest [3-6].

In the present study, 10 patients experienced anesthesiacontributory death, with an incidence of 2.1/10,000 anesthetics, and this incidence is higher than that reported in a study from the USA $(0.22 / 10,000)$ [3]. This difference might be associated with differences in the study populations, including a smaller denominator, and the definitions of anesthesia-related death and anesthesia-contributory death. In addition, there was no anesthesia-related death in the present study, resulting in an increase in the incidence of anesthesia-contributory death. Furthermore, the rate of emergency surgery was higher among patients who experienced nonanesthesia-related death than among those who experienced anesthesia-contributory death. This might be because patient status, such as preoperative

Table 3 The pathophysiological mechanisms and details of patients who experienced anesthesia-contributory death

\begin{tabular}{|c|c|c|c|c|c|c|c|c|}
\hline Number & $\begin{array}{l}\text { Age } \\
\text { (year) }\end{array}$ & $\begin{array}{l}\text { ASA- } \\
\text { PS }\end{array}$ & Emergency & Sex & $\begin{array}{l}\text { Period of the } \\
\text { event leading to } \\
\text { death }\end{array}$ & $\begin{array}{l}\text { Pathophysiological } \\
\text { process }\end{array}$ & Detailed description & $\begin{array}{l}\text { Location of the } \\
\text { event leading to } \\
\text { death }\end{array}$ \\
\hline 1 & 78 & V & Yes & Male & Maintenance & $\begin{array}{l}\text { Hypovolemia } \\
\text { (hemorrhage) }\end{array}$ & $\begin{array}{l}\text { Ruptured abdominal aortic aneurysm; intraoperative massive } \\
\text { hemorrhage and bradycardia }\end{array}$ & Operating room \\
\hline 2 & 92 & IV & No & Female & $\begin{array}{l}\text { Postoperative } \\
\text { period }\end{array}$ & $\begin{array}{l}\text { Hypovolemia (true } \\
\text { hypovolemia) }\end{array}$ & $\begin{array}{l}\text { Bowel obstruction due to transverse colon cancer; atrial } \\
\text { fibrillation with tachycardia and a large amount of intestinal } \\
\text { solution }\end{array}$ & General ward \\
\hline 3 & 75 & III & No & Male & $\begin{array}{l}\text { Postoperative } \\
\text { period }\end{array}$ & $\begin{array}{l}\text { Hypovolemia (true } \\
\text { hypovolemia) }\end{array}$ & $\begin{array}{l}\text { Hemodialysis; postoperative hyperkalemia; hemodialysis } \\
\text { difficulty due to hypovolemia }\end{array}$ & General ward \\
\hline 4 & 83 & V & Yes & Female & $\begin{array}{l}\text { Postoperative } \\
\text { period }\end{array}$ & $\begin{array}{l}\text { Hypovolemia } \\
\text { (hemorrhage) }\end{array}$ & $\begin{array}{l}\text { Ruptured abdominal aortic aneurysm; hypotension shortly } \\
\text { after anesthesia induction; massive hemorrhage }\end{array}$ & Intensive care unit \\
\hline 5 & 48 & V & Yes & Male & $\begin{array}{l}\text { Postoperative } \\
\text { period }\end{array}$ & $\begin{array}{l}\text { Hypovolemia } \\
\text { (sepsis) }\end{array}$ & $\begin{array}{l}\text { Multiple organ failure and hypotension after replacement of } \\
\text { the ascending aorta }\end{array}$ & Intensive care unit \\
\hline 6 & 70 & V & Yes & Male & Maintenance & $\begin{array}{l}\text { Hypovolemia } \\
\text { (hemorrhage) }\end{array}$ & $\begin{array}{l}\text { Ruptured abdominal aortic aneurysm; intraoperative massive } \\
\text { hemorrhage }\end{array}$ & Operating room \\
\hline 7 & 59 & III & No & Male & Maintenance & $\begin{array}{l}\text { Myocardial } \\
\text { infarction }\end{array}$ & $\begin{array}{l}\text { History of angina pectoris; intraoperative ventricular } \\
\text { fibrillation following ST-elevation; possibility of cardiac } \\
\text { ischemia }\end{array}$ & Operating room \\
\hline 8 & 74 & V & Yes & Female & Maintenance & $\begin{array}{l}\text { Myocardial } \\
\text { infarction }\end{array}$ & $\begin{array}{l}\text { Aortic dissection with mitral valve regurgitation; low output } \\
\text { syndrome; myocardial infarction on cardiology }\end{array}$ & Intensive care unit \\
\hline 9 & 12 & III & Yes & Male & Maintenance & Arrhythmia & $\begin{array}{l}\text { Perforation of a stress ulcer; burn; ventricular fibrillation } \\
\text { caused by hyperkalemia after transfusion }\end{array}$ & Intensive care unit \\
\hline 10 & 88 & IV & Yes & Male & $\begin{array}{l}\text { Postoperative } \\
\text { period }\end{array}$ & Respiratory failure & $\begin{array}{l}\text { Bladder hemorrhage and anemia with multiple } \\
\text { comorbidities; hypoxia after surgery }\end{array}$ & Operating room \\
\hline
\end{tabular}


comorbidity, has greater effects on death when compared with anesthesia.

Among the 10 patients who experienced anesthesiacontributory death, 4 pathophysiological processes were identified. Hypovolemia is one of the most common complications during anesthesia, and almost all cases are managed well. Hypovolemia caused by rapid massive hemorrhage and large leakage into the tissues can lead to serious consequences, although this is rare. Perioperative acute myocardial infarction rarely occurs in patients undergoing noncardiac surgery, but it has been shown to be strongly associated with in-hospital mortality [12]. One patient was suspected of ST-elevation myocardial infarction (case 7 in Table 3), and this patient had a history of angina pectoris. Another patient presented with acute myocardial infarction postoperatively (case 8 in Table 3), and this patient underwent aortic surgery owing to aortic dissection. Acute myocardial infarction might be caused by aortic dissection; however, this case was included in the anesthesia-contributory death group because we were unable to exclude inadequate oxygen delivery following perioperative low output syndrome. Arrhythmia caused by hyperkalemia after transfusion might be preventable with frequent blood analysis. The etiology of postoperative respiratory failure is unknown. However, it might be caused by preoperative multiple comorbidities, including anemia, heart failure, and kidney injury.

The limitations of this study include its representation of perianesthetic death from a single institution. Our institution is a 992-bed tertiary hospital and includes a trauma center, but there are no organ transplantation surgeries, except for kidney transplantations. The rate of perianesthetic death can vary depending on the institution and study population. Additionally, the data were evaluated retrospectively, and thus, we experienced missing data and analyzed limited data. Moreover, death and pathophysiological processes were classified independently by two researchers, and they consulted with another researcher at the time of disagreement. The decisions might be different for other anesthesiologists.

\section{Conclusion}

The incidence of perianesthetic death in this study performed at a Japanese tertiary hospital over a period of 10 years was 8.8/10,000 anesthetics. Additionally, no patient experienced anesthesia-related death, 10 experienced anesthesia-contributory death, and 31 experienced nonanesthesia-related death. The most common event leading to anesthesia-contributory death was hypovolemia, followed by myocardial infarction, arrhythmia, and respiratory failure. In the future, a further study using a large database with exact information is required to analyze the epidemiology of perianesthetic death and reduce its rate.
Abbreviations

ASA-PS: American Society of Anesthesiologists-Physical Status; Cl: Confidence interval

\section{Acknowledgements \\ None}

\section{Authors' contributions}

MS and YN collected the patients' data. Ml conducted the statistical analyses, drafted the manuscript, and obtained the approval from the Institutional Review Board. YN and MK revised and edited the manuscript. All authors contributed to and approved the final version of the manuscript.

\section{Funding}

This research did not receive any specific grant from funding agencies in the public, commercial, or not-for-profit sectors.

\section{Availability of data and materials}

They are available as a spreadsheet file upon reasonable request.

\section{Ethics approval and consent to participate}

This retrospective observational study was approved by the Institutional Review Board of Nara Medical University (Kashihara, Nara, Japan; Chairperson Prof. M. Yoshizumi; approval no. 2964; December 17, 2018). The requirement of informed consent was waived because of the retrospective nature of this study.

\section{Consent for publication}

Not applicable

\section{Competing interests}

The authors declare that they have no competing interests.

Received: 13 January 2020 Accepted: 27 January 2020

Published online: 05 February 2020

\section{References}

1. Nepogodiev D, Martin J, Biccard B, Makupe A, Bhangu A. National Institute for Health Research Global Health Research Unit on Global Surgery. Global burden of postoperative death. Lancet. 2019;393:401.

2. Lagasse RS, Steinberg ES, Katz RI, Saubermann AJ. Defining quality of perioperative care by statistical process control of adverse outcomes. Anesthesiology. 1995;82:1181-8.

3. Pollard RJ, Hopkins T, Smith CT, May BV, Doyle J, Chambers CL, et al. Perianesthetic and anesthesia-related mortality in a southeastern United States population: a longitudinal review of a prospectively collected quality assurance data base. Anesth Analg. 2018;127:730-5.

4. Hohn A, Machatschek JN, Franklin J, Padosch SA. Incidence and risk factors of anaesthesia-related perioperative cardiac arrest: a 6-year observational study from a tertiary care university hospital. Eur J Anaesthesiol. 2018;35: 266-72.

5. Ellis SJ, Newland MC, Simonson JA, Peters KR, Romberger DJ, Mercer DW, et al. Anesthesia-related cardiac arrest. Anesthesiology. 2014;120:829-38.

6. Sobreira-Fernandes D, Teixeira L, Lemos TS, Costa L, Pereira M, Costa AC, et al. Perioperative cardiac arrests-a subanalysis of the anesthesia-related cardiac arrests and associated mortality. J Clin Anesth. 2018;50:78-90.

7. Kawashima Y, Takahashi S, Suzuki M, Morita K, Irita K, Iwao Y, et al. Anesthesia-related mortality and morbidity over a 5-year period in 2,363,038 patients in Japan. Acta Anaesthesiol Scand. 2003;47:809-17.

8. Lienhart $A$, Auroy $Y$, Péquignot $F$, Benhamou D, Warszawski J, Bovet $M$, et al. Survey of anesthesia-related mortality in France. Anesthesiology. 2006;105: 1087-97.

9. Hove LD, Steinmetz J, Christoffersen JK, Møller A, Nielsen J, Schmidt H. Analysis of deaths related to anesthesia in the period 1996-2004 from closed claims registered by the Danish Patient Insurance Association. Anesthesiology. 2007;106:675-80.

10. Hopkins TJ, Raghunathan K, Barbeito A, Cooter M, Stafford-Smith M, Schroeder R, et al. Associations between ASA Physical Status and postoperative mortality at $48 \mathrm{~h}$ : a contemporary dataset analysis compared to a historical cohort. Perioperative Medicine (London). 2016;5:29. 
11. Whitlock EL, Feiner JR, Chen LL. Perioperative Mortality, 2010 to 2014: A retrospective cohort study using the National Anesthesia Clinical Outcomes Registry. Anesthesiology. 2015;123:1312-21.

12. Smilowitz NR, Gupta N, Guo Y, Berger JS, Bangalore S. Perioperative acute myocardial infarction associated with non-cardiac surgery. Eur Heart J. 2017; 38:2409-17.

\section{Publisher's Note}

Springer Nature remains neutral with regard to jurisdictional claims in published maps and institutional affiliations.

Submit your manuscript to a SpringerOpen ${ }^{\circ}$ journal and benefit from:

- Convenient online submission

- Rigorous peer review

- Open access: articles freely available online

- High visibility within the field

- Retaining the copyright to your article

Submit your next manuscript at $\boldsymbol{\sim}$ springeropen.com 